\title{
Complexity Theory and CALL Curriculum in Foreign Language Learning
}

\author{
Hassan Soleimani \\ Department of Applied Linguistics, Payame Noor University, Tehran, Iran \\ POB: 19395-4697 \\ E-mail: Arshia.soleimani@gmail.com \\ Farnaz Farrokh Alaee (Corresponding author) \\ Payame Noor University, Tehran \\ E-mail: farnaz.alaee@yahoo.com
}

Received: 02-12-2013

doi:10.7575/aiac.ijalel.v.3n.3p.19
Accepted: 07-01-2014

Published: 01-05-2014

URL: http://dx.doi.org/10.7575/aiac.ijalel.v.3n.3p.19

\begin{abstract}
Complexity theory literally indicates the complexity of a system, behavior, or a process. Its connotative meaning, while, implies dynamism, openness, sensitivity to initial conditions and feedback, and adaptation properties of a system. Regarding English as a Foreign/ Second Language (EFL/ESL) this theory emphasizes on the complexity of the process of teaching and learning, including all the properties of a complex system. The purpose of the current study is to discuss the role of CALL as a modern technology in simplifying the process of teaching and learning a new language while integrating into the complexity theory. Nonetheless, the findings obtained from reviewing previously conducted studies in this field confirmed the usefulness of CALL curriculum in EFL/ESL contexts. These findings can also provide pedagogical implications for employing computer as an effective teaching and learning tool.
\end{abstract}

Keywords: Second/foreign language curriculum, CALL, Complexity theory

\section{Introduction}

Complexity theory sheds a new light on Second/Foreign Language Learning (S/FLL). According to Hashamdar (2012) the idea of complexity theory comes from 1960s work of meteorologist Edward Lorenz. Lorenz designed a simple climate model including some differential equations. To save time and space, he rounded the original inputs of a set of equations of weather temperature, pressure, wind and ect. from six decimal-digits to three decimal-digits. Lorenz believed that this change (rounding the inputs) would not cause any change on the result, so he tried to reexamine the idea. Surprisingly he found that the second run was completely and dramatically different from the first one. He discovered that even tiny differences in initial conditions would cause large changes in the weather predicted. This discovery, sensitivity to initial conditions, is one of the basic features of complexity theory. According to complexity theory, small differences in input can result in large differences in outcome (Finch, 2001). This theory has been widely used in many fields of study especially science. It has been used in the social sciences and applied linguistics recently (Hashamdar, 2012).

Prediction has no room in complexity theory; instead, it mostly concerns with explanation. It aims to explain how complex systems emerge and are maintained (Nelson, 2011). In the field of second language research (SLR), LarsenFreeman (1997, as cited in Nelson, 2011) in her article entitled "Chaos/Complexity Science and Second Language Acquisition" suggests that complexity theory gave us a new perspective on second language acquisition by "cast[ing] several enduring SLA conundrums in a new light" (Nelson, 2011, p.141). Ahmadi (2011) views language as a complex system like other dynamic nonlinear ones; since, it meets the two main criteria of complexity, that is, first, it consists of a variety of subsystems such as phonology, morphology, lexicon, syntax, semantics and pragmatics. Second, these subsystems are interdependent.

However, with no doubt, complexity theory helps us design language tasks through providing us with another way of looking at language. One would feel that a complex systems approach does not in the first instance provide us with an alternative design for our teaching, but rather a novel view of language. It is the impacts of taking this perspective seriously that might influence language teaching design (Weideman, 2009).

Due to the critical importance of curriculum in education in general, and in EFL settings, in specific, it seems of a great significance to redefine complexity theory in terms of curriculum designed for educational purposes in EFL contexts. Wang and Cheng (2005) stress on the need for global curriculum reform in general education and specifically in the field of teaching English as a foreign language (TEFL). Recent innovations concentrate on the implementation of computer technology in redesigning curricula. Using computer as an effective teaching and learning tool a new discipline called Computer Assisted Language Learning (CALL) has been introduced to EFL context. Development of new curriculum based on CALL is very young and requires EFL instructors and learners alike to be equipped with 
appropriate multidimensional knowledge of computer science. Regarding the significance of integrating CALL activities into the existing curriculum, teachers should be sure about the accessibility of CALL programs based on the learners' level of language and their digital literacy (Park \& Son, 2009).

In the present study eeforts were made to investigate the marriage of EFL curriculum with CALL in educational contexts. In particular, the major tenets of complex system theory will be applied to the CALL curriculum in EFL language teaching and learning context, and we will clarify how CALL can simplify the utility of complexity theory in EFL learning and teaching processes.

\section{Review of Literature}

\subsection{Complexity Theory and Complex Systems}

Complexity theory deals with complex systems and these systems entail some main characteristics as, sensitivity to initial conditions and feedback, dynamism, non-linearity, openness, complexity and self-organizing ability (adaptation). Complex systems are sensitive to initial conditions which can cause a change in long-term behavior that is called "Butterfly effect" (Larsen-Freeman \& Cameron, 2008). The complex systems are chaotic; the term "chaos" indicates the seemingly disordered system which tries to find out the underlying order of the apparently random data (Ahmadi, 2011). A chaotic system will be affected by outside energies during the process of self-organization of its patterns (adaptation) (Gell-man, 1994, cited in Soleimani \& Alavi, 2013). These systems are non-linear; that is, the ultimate behavior of the system is not sum of the behaviors of individual members (components) (Soleiman \& Alavi, 2013). So the outcome related to these systems is unpredictable. Dynamism (changing overtime) is another characteristic of the complex systems which deals with adaptation and sensitivity to feedback (Larsen-Freeman \& Cameron, 2008). The system of language is considered as a complex system since it is dynamic (changes over time) for example during the process of language acquisition the learner restructures his/her system of grammar by responding to income data/input, part of which is feedback and correction (Hashamdar, 2012). Complexity theory aims to find the reasons lied behind the system's collective behavior which is the result of interacting individuals' behaviors within the system and interacting of the system with its environment (Larsen-freeman \& Cameron, 2008).

\subsection{Complexity Theory and SLA Curriculum}

Language is considered as a complex system since it has all the properties of a complex system: it comprises various components including semantics, syntax, phonology and morphology which are interacting and are open to change overtime (Soleimani \& Alavi, 2013). Second language classroom is a social context. According to Breen (2001) language classroom cannot be metaphorically referred to as an experimental laboratory since it does not deal with predictable output as a result of selected input. He believes that there is an intervening variable which has effect on the relationship between input (independent variable) and output (dependent variable). This intervening variable includes learners' and teacher's socio-economic and cultural background, their interactions in the classroom and outside influences (society impact). This idea reconfirms the complex nature of the SLA classroom. In this relation, Soleimani and Alavi (2013) have investigated SLA research applying complexity theory. They have defined SLAR (second language acquisition research) considering its complex nature; it is assumed as a network of agents (animate beings as teachers and learners) and elements (inanimate beings as methodology and materials) that are interacting in the ecosystem of the research and some other variables which are unpredictable and uncontrolled. According to them, research in second language area is dynamic and changes overtime as it is influenced by the characteristics of the components (elements and agents) of the system and their interactions with each other and with the ecosystem.

Taking the characteristics of SLA classroom into account, the SLA curriculum can be defined based on complexity theory. Here the agents of this complex changing network (SLA classroom) are teacher and students and the elements are materials, teaching procedures, assessments and teaching aids to name a few. These components (agents and elements) are interacting in the ecosystem of language classroom over time, that is, the classroom life is dynamic and the students' and teacher's subjective (personal) and inter-subjective (collective) experiences (Breen, 2001) in negotiating with the elements always create unpredictable and new realities as outputs. The rules and beliefs dominant in the society can be taken in by the classroom life and considered as another kind of feedback (outside of the system) to help the system to self-organize and self-regulate to produce order (adaptation).

Blackman (2008) believes that complexity theory provides a new perspective on curriculum design and application, especially in the area of Teaching English as a Second Language (TESL). Since language learning is a flexible process, teachers must be able to react in real time to factors beyond their control. Rather than viewing such factors as interruptions to a closed system, teachers can decide about what to focus upon and what to gloss over, when to pick up the pace and when to slow down, finding a natural rhythm which is helpful in creating a symbiotic relationship with the learners, the classroom and the university or school structure.

Put it in a nutshell, regarding complexity theory, SLA curriculum is not so static and fixed as the traditional curriculum; while, it is dynamic and open to change based on the immediate situation of the classroom. This type of curriculum is mostly based on the shared decision made by teacher and students in the real context of the classroom. Teachers in the classroom life should not trust on any pre-set curriculum and should be an action researcher to decide correctly in time (Hall, 2011). Because of this the methodology and curriculum of an experienced teacher never can be predicted since it is changing during the process of teaching and learning in the ecosystem of language classroom (Hall, 2011). 


\subsection{Computer Assisted Language Learning (CALL) and Curriculum development in SLA}

CALL is defined as "the search for and study of applications of the computer in language teaching and learning" (Levy, 1997, p.1) or "any process in which a learner uses a computer and, as a result, improves his or her language" (Beatty, 2003 , p. 7). And curriculum is "an overall plan for a course or program" it includes the educational purposes, content, teaching procedures, learning activities, assessments and evaluation related to that program (Richards \& Schmidt, 2002, p. 139). Integrating CALL into the SLA curriculum will cause changes in the components of the curriculum which are the content, materials, teaching procedures, learning activities and even the type of assessment and evaluation.

Nguyen (2008) believes that using internet can provide good possibilities and opportunities for teachers and learners of a foreign language to have access to up-to-date language materials and authentic language resources. Many changes will happen to the roles of teacher and learners too. Teachers are not considered as providers of information anymore and nor do the students as recipients. Through self-access to WWW learners are capable of providing authentic materials independently and actively (Nguyen, 2008). The teachers, instead, are more considered as consolers and active participants. Assessment and feedback will be web-based too. As discussed before these changes would affect all the curriculum steps.

Besides the benefits, some problems are imposed on curriculum while integrating into CALL programs. Park and Son (2009) investigated teachers' perceptions and perspectives about implementation of CALL in EFL classroom. To achieve the goals of this an interview-based questionnaire was designed. Twelve Korean in-service teachers of EFL in Korea were selected as the participants. According to five teachers who took part in the study, the limitations imposed by curricula make it difficult and demanding to go through. The participants stated that integrating CALL resources into the existing curricula is very difficult. Overall, the participants believed that time limitation, lack of digital literacy and insufficient facilities in school, inhibited them to integrate CALL into their language classroom practice. They also stated that teachers were responsible to teach the text books which were not organized based on CALL. In general Park and Son's findings (2009) revealed that all teachers are optimistic toward the future of CALL. Considering all the contextual problems, including insufficient facilities, class size and limited flexibility in curriculum, teachers yet believed in the use of CALL in future as an inevitable part of SLT/FLT. Four teachers; however, emphasized on the appropriateness of the textbooks and flexibility of the curricula for CALL contexts. Another obstacle to CALL implementation found in their study is the implication of online sources. In order to integrate technology-based teaching to existing curricula, educators should be able to use and to teach how to use new software which are in line with textbooks (Park \&Son, 2009).

In his study, Sehlaoui (2001) emphasizes on the enhancement of communicative competence by integrating computerbased programs into EFL/ESL contexts. This author states that though the ESL/EFL teacher education programmers mostly aware of repercussions of technology on culture, they again insist on integrating computer-based technologies into their curricula. So in this case the responsibility is put on the half of the users to take cultural care by critically analyzing the technological programs. This cultural effect indicates the power of the dominant culture, which has been referred to, according to Phillipson (1992) as linguistic imperialism. Such cultural impact should be included in the TESOL curriculum while integrating into technology (Phillipson, 1992, cited in Sehlaoui, 2001).

Similarly, Kim (2008) argues that integrating CALL into language classrooms includes a variety of issues of language teaching, like pedagogical approaches, language skills, learning styles, students' target language proficiency levels, and motivation. While adding CALL into classroom practice, some essential factors should be concerned, e.g. teachers' perception on CALL communication; whether it is authentic and meaningful (Warschuer, 1996b), or their visualization of CALL practice; whether they are learner- or teacher-centered (cited in Kim, 2008).

Based on the theories from the sociolinguistic perspective of second language learning, an online chat-based curriculum was developed by Lee (2005). Lee's curriculum emphasized on developing learners' communicative competence through blended learning, online chat and small group classroom chat. This blended type of curriculum aimed to improve students' oral communicative skills. According to most of Lee's participants the curriculum was very effective in improving oral communication. Chat-based instruction, compared to textbook instruction, seemed more attractive, relevant and effective. The findings indicated that as a result of receiving such treatment, learners identified their habitual errors made in oral language. Participants, also, emphasized on the importance of tailored instruction, emphasizing on the effectiveness of mixing of online and classroom chatting. Regarding learners' motivation, it was found that chat-based activities might increase the tendency to participate in face-to-face communication. They believed that they would become able to use their practiced communication in natural setting; because of the similarities between these two conditions: use of colloquial language and synchronous communication (Lee, 2005).

\subsection{Complexity Theory and CALL Curriculum}

Regarding CALL history, there are three phases named: "Restricted", "Open" and "Integrated" CALL (Bax, 2003). In the first phase which exists during the 1970s-1980s, the technology was mainframe and the teaching paradigm was GTM and ALM. Most of the practices at that time were drills and repetition exercises. In this phase, accuracy was very important (Bax, 2003). The second phase, "Open CALL", indicates the use of computers for communicative purposes during the 1990s. It views language as a cognitive system which is mentally constructed. During this phase both accuracy and fluency are considered as important factors. To some scholars, we are now at this phase (Bax, 2003). The third phase, "Integrated" CALL $\left(21^{\text {st }}\right.$ century), is associated with the Internet and web $2.0^{\mathrm{i}}$ services. This phase looks at 
language as a socio-cognitive process and focuses on content-based materials and authentic discourses. Accuracy, fluency and agency are important factors in learning at this phase (Bax, 2003).

The technology goes towards the third phase, that is use of CALL as an integrated part of the syllabus in education. This will happen through "normalization" (Bax, 2003). This tendancy towards integration of CALL into the EFL/ESL curriculum will affect all the factors within the educational system. Regarding the third phase, teaching materials should be authentic and activate learners' sense of agency (responsibility) (Thomas, 2009). The learners have active participation and interaction using Web 2.0 activities such as Face book, chat rooms or Moo (Thomas, 2009). This active participation may cause a kind of disorder, chaos, for the learner who interacts with the authentic materials on one side and the other learners and teacher on the other side. Then after a while, he/she tries to come to a kind of order (equilibrium), which is the process of learning a new language and adaptation with the environment (Larsen-Freeman \& Cameron, 2008). Nothing is predictable or predetermined (non-linearity) in Web 2.0 activities (Larsen-Freeman \& Cameron, 2008). Learners are real agents, responsible about their own learning process, and active participants. They are able to have their own identity and voice and to be heard by the other users of WWW, agency (Thomas, 2009) so they can change the environment/ecosystem of their learning on one hand and adapt themselves to it on the other hand (dynamism and adaptation). Each learner has his/her own interest and characteristics (diversity), but s/he belongs to the same class with the other learners and should reach to the same understanding (unity), that is unity in diversity. These are characteristics of a complex system mentioned by Larsen-Freeman and Cameron (2008).

From Johnson's (2006) work, it appears that computer-network based tools will enhance learners' cooperative skills. This study took data from two different graduate seminars at the University of Arizona where computer-mediated learning has been integrated into the classroom activities and curriculum. Such blended learning context, confirms the dynamic nature of language acquisition, which is the central idea in dynamic systems theory (also known as complexity or chaos theory) as discussed by Gleick (1988) and Larsen-Freeman (1997). This model provides some guidelines to clarify the non-linearity and complexity nature of language as a social entity (cited in Larsen-Freeman \& Cameron, 2008). The complexity theory indicates the fall and rise of a natural process as it happens in a real context. The complex system needs energy of all the agents in the educational setting, who are teachers and learners, syllabus designers and the other participants, that is so called synergy . Language learning/teaching process is not predictable, that is nothing in the classroom context is static or predetermined based on the complexity theory, this idea implies the notion of strange attractor (See Table 1).The CMC (Computer Mediated Communication) when applied to complexity theory in language learning settings should not ignore the characteristics of the complex systems.

Table 1. Complexity theory and CMC.

\begin{tabular}{ll}
\hline $\begin{array}{l}\text { Features Of A Complex, } \\
\text { Dynamic System }\end{array}$ & Applied To Interaction And Learning In A CMC Environment \\
\hline $\begin{array}{l}\text { Sensitive to Initial } \\
\text { Conditions }\end{array}$ & $\begin{array}{l}\text { Student identities, needs, trajectories. Syllabus. Materials. Context etc. Necessarily } \\
\text { different for each class }\end{array}$ \\
\hline $\begin{array}{l}\text { Dynamic, Open } \\
\text { Complex, Emergent }\end{array}$ & $\begin{array}{l}\text { System evolves over the semester as individual students interact with their learning } \\
\text { environment and initial conditions }\end{array}$ \\
$\begin{array}{l}\text { Composed of many diverse individuals that interact in non-linear and unpredictable } \\
\text { ways. Resistance can be seen as chaotic turbulence out of which a new order may } \\
\text { emerge }\end{array}$ \\
\hline $\begin{array}{l}\text { Self-Organizing } \\
\text { Adaptive }\end{array}$ & $\begin{array}{l}\text { Shirts in behavior in student learning and interaction patterns will occur throughout } \\
\text { the semester }\end{array}$ \\
\hline Feedback Sensitive & $\begin{array}{l}\text { The members of the class also belong simultaneously to many other systems and } \\
\text { will bring their ideas and suggestions into the system asit progresses. The Instructor } \\
\text { may also provide 'feedback' in the traditional understanding }\end{array}$ \\
\hline Strange Attractors & $\begin{array}{l}\text { The path that the class postings/discussions and learning takes through the semester } \\
\text { is not predictable }\end{array}$ \\
\hline Fractal & $\begin{array}{l}\text { Levels of interaction and activity within the system will be reflected at different } \\
\text { time scales throughout the semester of participation. The similar patterns that } \\
\text { emerge suggest continuous shifts and dynamism }\end{array}$ \\
\hline
\end{tabular}

(Larsen-Freeman, 1997, cited in Johnson, 2006, p.25)

The above Table presents the characteristics of complexity theory when applied to CMC.

\section{Discussion}

The current study mainly focused on the importance of modern technology in EFL/ESL curriculum as well as on a discussion in order to find the status of complexity theory in such contexts. The succinct paper tries to show how the integration of CALL into the complexity second/foreign language curriculum can simplify the language teaching and learning processes. 
To find relevant ideas a review-based study was conducted and a variety of already performed studies were scrutinized and effective data were gleaned. The data confirmed the application of computer as an effective teaching and learning tool in EFL/ESL contexts. Considering foreign language acquisition as a complex task, helpful ways should be introduced in and brought into this arena in order to provide its members (both teachers and learners) with equipment and tools so that the results may be extraordinary. Review of related works confirmed the usefulness of computer use in $\mathrm{EFL} / \mathrm{ESL}$ classes.

The integrating of CALL into the language learning curriculum regarding the properties of complexity theory can simplify the process of second/foreign language learning and teaching. In this regard, the components of the curriculum (the elements and the agents) are defined based on CALL and complexity theory. The elements of the curriculum, educational goals, materials, feedbacks and assessment, teacher's and learners' roles, teaching and learning processes (Richards \& Schmidt, 2002) will be influenced using CALL and complexity theory:

a. The main characteristic of an educational curriculum is that it is pre-planned, before the presentation of materials. So the classroom affairs are predictable while the complexity curriculum is not a priori but a posteriori.

b. The materials are authentic and up-to-date (Nguyen, 2008) using WWW and online services, there is a possibility of chatting a real communication through $\mathrm{MOO}$ and internet-based chat rooms, the students have a free access to authentic audio-video materials using podcasts (Hegelheimer \& O’Bryan, 2009). In this case the learners are exposed to a large amount of input which may cause complexity and chaos in the first steps but little by little they can self-organize their learning process by feedbacks from their teacher or other learners. In a shared decision manner, they will be able to select topics or materials of their interest so they will be more motivated to learn.

c. Feedbacks can be immediate through chatting or with some delay using e-mail (Brandl, 2002). The classroom life as a complex system is sensitive to feedback in order to reach a kind of self-organization or equilibrium.

d. d. Assessment as another element of the curriculum will be revolutionized to an adaptive and dynamic process based on complexity theory. CALL can help this process so that the system is sensitive about feedbacks and the online assessment would not let the learners to be alone during the process of evaluation. The mediator, teacher or the system, will provide some hints for the learners to adapt themselves during the process of dynamic assessment. The use of computer as mediator can help learners to go beyond their independent performance and indicates what the students can do in cooperation rather than isolation.

e. The role of teachers regarding the new curriculum will be changed too; since the system is not traditional teacher-centered process; while, it will welcome the learners' voices and decisions on material development, methodology, assessment and etc. Using CALL, the learners have access to a wide range of materials and the teacher will select the topic which is of interest of the learners and can be searched by them easily (Nguyen, 2008). Learning and teaching language is a 'fluid process', an ongoing process, so the teacher must be able to handle the classroom when there are factors beyond the scope of class and to act in real time (Blackman, 2008). The demanding and important role of the teacher as a mediator and source of feedback should not be undertaken.

f. Learners will be more responsible (have agency) about their process of learning. Their role will be changed into active participants. They should choose the topics and select the related materials. They can search materials online, using internet search engines. The teacher and the students together, in a shared decision, will select the topics and materials to work on it. The process of choosing relevant, effective and appropriate input is a demanding and sensitive job for teacher and learners and may cause disorder at first, but little by little learners ,by the help of the experienced teacher, will make order and come to equilibrium, learning.

Another point worth mentioning is that the agents of the educational system (the members) need to receive effective instructions regarding how to employ computer as a facilitator in the way of teaching and learning. Lack of digital literacy on one hand, can result in harmful outcomes such as despair, stress, decreased interest and self-confidence and so on. On the other hand, based on complexity theory, the system may increase the complexity of difficulty of foreign language acquisition. EFL/ESL curriculum designers should include effective instructions (teacher training) regarding up-to-date software and the way to implement them.

The discussion provide indications that CALL curriculum can help the complexity theory to be applied in EFL/ESL teaching and learning processes; however, it should not be forgotten that implementation of technology like computer in EFL/ESL settings need a plenty of requirements. As mentioned above EFL/ESL teachers and students alike, prior to employment of computer as an educational aid, should be trained, accordingly.

\section{Conclusion}

The present review goes through the prime aim of integrating complexity theory into CALL curriculum and as mentioned in the above sections the language classroom life is a social dynamic system which is not static and teaching and learning processes within this social entity are part of an adaptive system during which a new unpredicted behavior will be acquired/created. It seems that, as it was discussed before; these processes (teaching and learning processes) can be simplified using CALL, since the properties of complex systems are coincided the characteristics of CALL curriculum. For example, to name a few, complex systems are sensitive to feedbacks which can be easily and 
immediately provided by the computer (online and immediate, or by some delay), the systems are also sensitive to initial conditions and chaotic processes that might be provided by the access to large amount of data on WWW (Nguyen, 2008) and then the agents, here the teacher and the students, seek a kind of equilibrium or underlying order by shared decisions, that is synergy, which help them to acquire an unpredicted and totally new reality, so called a new language (Hall, 2011). As concluded there is no pre-written syllabus to deal with; while, it will be made during the process of teaching and learning based on a shared decision and cooperation that is the syllabus will be a priori. Assessment in complexity-CALL curriculum will be dynamic and adaptive: providing immediate feedbacks by computer as a mediator and changing the level of difficulty of the questions based on the learners' level of proficiency. Based on these discussions, the "Integrated" CALL (Bax, 2003) can be best suited to the complexity curriculum in $\mathrm{EFL} / \mathrm{ESL}$ context. Further research is suggested to scrutinize if sub-categories of the computer including internet, specific softwares, weblogs, social networks and so on can decrease the complexity of a variety of language skills. Hopefully, the present findings will be helpful for future researchers, curriculum designers, EFL/ESL teachers and students and will pave the way for further investigations.

\section{References}

Ahmadi, A.R. (2011). Chaos Theory and Language Assessment: The effect of Sensitivity to Initial Conditions on Test Performance. International Journal of Humanities and Social Science, 1(17), 293-296.

Bax, S. (2003). CALL: Past, present and future. System, 31, 13-28.

Beatty, K. (2003). Teaching and researching computer-assisted language learning. New York: Longman. Retrieved April 24, 2013, from http://www.amazon.com/Teaching-Researching-Computer-Assisted-LanguageLinguistics/dp/1408205009.

Blackman, P. (2008). A New Science Look at Negotiating Curriculum and Classrooms. An International Journal of Complexity and Education, 5 (1), 141-148.

Brandl, K. (2002). Integrating internet-based reading materials into the foreign language curriculum: from teacher- to learner-centered approaches. Language Learning and technology, 6 (3), 87-107.

Breen, M. P. (2001). The social context for language learning a neglected situation? In C. N. Candlin \& N. Mercer (Eds), English language teaching in its social context A reader (pp. 122-144). London and New York: Routledge.

Finch, A. E. (2001). Complexity in the language classroom. Secondary Education Research, 47, 105-40.

Hall, G. (2011). The language classroom in theory and practice: complex, diverse and 'local'. In R. Carter \& G. Cook (Eds), Exploring English language teaching in action (pp. 38-57). London: Routledge.

Hashamdar, M. (2012). First Language Acquisition: Is It Compatible with Chaos/Complexity Theory? Theory and Practice in Language Studies, 2(7), 1503-1507.

Hegelheimer, V., \& O'Bryan, A. (2009). Mobile technologies, podcasting and language education. In M. Thomas (Ed.), Handbook of research on Web 2.0 and second language learning (pp. 331-349). USA: Yurchak Printing Inc.

Johnson, N. (2006). Promoting Emergent Understanding and Knowledge: Computer-Mediated Communication From A Complexity Theory Perspective. Arizona Working Papers in SLAT( 13), 19-36.

Kim, H.K. (2008). Beyond Motivation: ESL/EFL Teachers' Perceptions of the Role of Computers. CALICO Journal, 25 (2), 241-259.

Larsen-Freeman, D. (1997). Chaos/complexity science and second language acquisition. Applied Linguistics, 18 (2), 141-165.

Larsen-Freeman, D., \& Cameron, L. (2008). Complex systems and applied linguistics. UK: Oxford University Press.

Lee, Y. (2005). Implementing Synchronous Chat-Based Curriculum in An Advanced-Level ESL Classroom. Ph D Thesis. Nova Southeastern University, USA Retrieved April 22, 2013, from: http://repository.lib.ncsu.edu/ir/bitstream/1840.16/4956/1/etd.pdf.

Levy, M. (1997). CALL: Context and conceptualization. Oxford: Oxford University Press. Retrieved April 12, 2013, from http://books.google.com/books/about/Computer_Assisted_Language_Learning.html?id=RRGgrjteVjUC

Nelson, C. (2011). The Complexity of Language Learning. International Journal of Instruction, 4 (2), 93-112.

Nguyen, L. V. (2008). Technology-enhanced EFL syllabus design and materials development. English Language Teaching, 1(2), 135-142.

Park, C.N.,\& Son, J.B. (2009). Implementing Computer-Assisted Language Learning in the EFL Classroom: Teachers' Perceptions and Perspectives. International Journal of Pedagogies and Learning, 5(2), 80-101.

Richards, J.C., \& Schmidt, R. (2002). Longman dictionary of language teaching and applied linguistics. U.K.: Pearson Education Limited.

Sehlaoui, A.S.(2001). Developing cross-cultural communicative competence via computer-assisted language learning: the case of pre-service ESL/EFL teachers. Alt-J, 9 (3), 53-64. 
Soleimani, H., \& Alavi, S.M. (2013). A dynamical system approach to research in second language acquisition. Journal of English Language Teaching and Learning, 11, 127-143.

Thomas, M. (2009). Handbook of research on Web 2.0 and second language learning. USA: Yurchak Printing Inc.

Wang, H., \& Cheng, L. (2005). The impact of curriculum innovation on the Cultures of teaching. The Asian EFL Journal Quarterly. 7( 4), 1-14.

Weideman, A. (2009). Uncharted territory: An emerging paradigm and the foundations of applied linguistics. Per Linguam, A Journal for Language Learning. Retrieved, April 4, 2013, from: http://www.allofliferedeemed.co.uk/Weideman/tuk05211.pdf.

\section{Note}

'Web 1.0 activities are those activities which only include publication without participation and it connects the information together and makes search engine. Such as Google search engine. But Web 2.0 activities include both publication and participation that is, the users can influence and be influenced by the other users such as Face book. This type of activities connect people together and make network of interactions (Thomas, 2009). 